\title{
Prevalence of Asymptomatic Brucellosis in Children 7 to 12 Years Old
}

\author{
Mohammad Aghaali, ${ }^{1}$ Siamak Mohebi, ${ }^{2}$ and Hosein Heydari ${ }^{3}$ \\ ${ }^{1}$ Qom University of Medical Sciences, Qom 3713649373, Iran \\ ${ }^{2}$ Department of Public Health, Qom University of Medical Sciences, Qom 3713649373, Iran \\ ${ }^{3}$ Pediatric Medicine Research Center, Qom University of Medical Sciences, Qom 3713649373, Iran \\ Correspondence should be addressed to Hosein Heydari; hoseinheydari3375@yahoo.com
}

Received 23 May 2015; Revised 28 September 2015; Accepted 1 October 2015

Academic Editor: Peter A. C. Maple

Copyright (C) 2015 Mohammad Aghaali et al. This is an open access article distributed under the Creative Commons Attribution License, which permits unrestricted use, distribution, and reproduction in any medium, provided the original work is properly cited.

\begin{abstract}
Background. Brucellosis is one of the most common diseases of humans and animals and its clinical manifestations differ from asymptomatic infection to chronic illness associated with recurrence of symptoms. This study aimed to evaluate the prevalence of brucellosis in asymptomatic children 7 to 12 years old in Kahak, Iran. Methods. In this study, 186 children 7 to 12 years old were evaluated. Demographic data and exposure to the brucellosis agent were recorded and blood samples for the Wright, Coombs, and $2 \mathrm{ME}$ tests were collected. All the study subjects were followed up for one year about the appearance of symptoms. Results. The mean age was $10 \pm 1.72$ years and $51 \%$ were boys. Family history was positive for brucellosis in $15 \%$ of children. A total of 8 children were brucellosis seropositive and, in subsequent follow-up, 6 of them showed the disease symptoms. Conclusion. This study showed that approximately $4.3 \%$ of children in endemic areas can have asymptomatic brucellosis and many of these children may be symptomatic in short term.
\end{abstract}

\section{Introduction}

Brucellosis is a zoonosis disease caused by the bacterial genus Brucella. That is transmitted directly or indirectly by contact with infected animals or contaminated dairy products. Its clinical manifestations vary from asymptomatic infection to chronic forms. Brucella species are small, gramnegative, nonmotile, nonspore-forming, and rod-shaped (coccobacilli) bacterial organisms and 8 species of them have been identified. Four of them have moderate-to-significant human pathogenicity and include Brucella abortus (from cattle; moderate pathogenicity), Brucella suis (from pigs; high pathogenicity), Brucella melitensis (from sheep; highest pathogenicity), and Brucella canis $[1,2]$.

Typically, humans contract disease by ingesting contaminated food, such as unpasteurized milk products, but can also acquire it through inoculation via direct contact with infected animals or animal parts and occasionally through occupational exposure in microbiology laboratories [1]. Clinical classifications of brucellosis are subclinical, acute, subacute, chronic, and localized brucellosis. Brucellosis affects various organs and has nonspecific symptoms such as fever, bone and muscle pain, weakness, sweating, weight loss, and headache [1].

It is endemic in Iran and the most common agent is Brucella melitensis [3]. In endemic areas, a high percentage of patients with brucellosis are asymptomatic and less than $10 \%$ of them are diagnosed following infection in the early stages $[4,5]$. Also in endemic areas, symptomatic patients only refer to health centers for diagnosis and treatment so asymptomatic patients remain carrier. These patients may present signs of infection in conditions such as reinfection or immune deficiency conditions [6].

In many countries, brucellosis is an occupational disease, which is uncommon in children. However, in Iran, because it is transmitted from animals to humans in nonoccupational ways, its prevalence in children is equal to adults or higher than them [7]. Clinical manifestations of brucellosis in children are like adults. However, being unfamiliar with the disease may be a delay in diagnosis [8]. By early diagnosis and 
TABLE 1: Distribution of risk factors for disease in children based on serological test result.

\begin{tabular}{|c|c|c|c|c|}
\hline Risk factor & Seronegative (178) & Seropositive (8) & Total (186) & $P$ value \\
\hline Animal contact & $27(15.16 \%)$ & $6(75.0 \%)$ & $33(17.7 \%)$ & $<0.001$ \\
\hline Dairy consumption & $46(25.84 \%)$ & $8(100.0 \%)$ & $54(29.0 \%)$ & $<0.001$ \\
\hline Family history of brucellosis & $24(13.48)$ & $4(50.0 \%)$ & $28(15.0 \%)$ & 0.005 \\
\hline
\end{tabular}

TABLE 2: Epidemiological and clinical data of the 6 symptomatic children.

\begin{tabular}{lcclcll}
\hline Patient & $\begin{array}{c}\text { Age } \\
\text { (years) }\end{array}$ & Gender & $\begin{array}{l}\text { Symptoms during } \\
\text { follow-up }\end{array}$ & $\begin{array}{c}\text { Time of symptoms } \\
\text { appearance (week) }\end{array}$ & Primary tests & $\begin{array}{c}\text { Family } \\
\text { history }\end{array}$ \\
\hline 1 & 8 & Boy & Fever and sweating & 8 & Wright 1/160 and 2ME 1/40 \\
2 & 7 & Boy & Knee pain & 30 & Coombs Wright 1/160 and Wright negative \\
3 & 9 & Boy & Abdominal and ankle pain & 22 & Coombs Wright $1 / 160$ and Wright negative & + \\
4 & 8 & Girl & Sacroiliitis & 12 & Coombs Wright 1/160 and Wright negative & - \\
5 & 10 & Boy & Abdominal and knee pain & 3 & Coombs Wright $1 / 80$ and Wright negative & + \\
6 & 10 & Girl & Knee pain & 8 & Wright $1 / 160$ and 2ME $1 / 40 \quad$ & - \\
\hline
\end{tabular}

effective treatment, many of these patients recover without any persistent complications. Given the high prevalence of brucellosis in Iranian children and the importance of diagnosing the asymptomatic patients, this study examined the prevalence of brucellosis in asymptomatic children 7 to 12 years old in Kahak, Iran.

\section{Methods}

This study was carried out at the first 6 months of 2013 in Kahak, Iran. The study population was all children aged 7 to 12 years. Children without a history of brucellosis and treatment for brucellosis and having typical signs of infection (fever, sweating, fatigue, and musculoskeletal pain) were included. Of 258 children, one hundred and eightysix elementary school children met the inclusion criteria. A physician did history taking and physical examination for signs and symptoms of the disease. Children were enrolled after informing them and their parents of the study plan and obtaining informed consent from parents. All eligible study subjects consented to participate. The study was planned according to the ethical guidelines following the Declaration of Helsinki and Ethics Committee of Qom University of Medical Sciences approved it.

None of the study subjects had a history of vaccination against brucellosis. After selecting study subject, demographic data, history of exposure to the brucellosis agent, and type of the exposure were recorded. Then, $5 \mathrm{~mL}$ of venous blood was obtained for the Standard Tube Agglutination Test (STA: Wright) and Coombs and 2-Mercaptoethanol (2ME) tests. Tube agglutination testing was carried out using the Pasteur-protocol kit (Iranian Institute for Health Sciences Research Co., Tehran). To perform the Wright test, serum was diluted to $1 / 1280$. Children with Wright test of $\geq 1 / 80$ and $2 \mathrm{ME}$ $\geq 1 / 40$ or Coombs Wright $\geq 1 / 80$ were considered positive. All children were followed up for one year about the appearance of symptoms and were examined by the physician every two months. Study subjects were given notices to prevent the disease during the follow-up period. Data was analyzed using SPSS version 20 with Chi square and Fisher's exact test.

\section{Results}

A total of 186 children were enrolled. The mean age was $10 \pm 1.72$ years. Minimum and maximum ages of the study subject were 7 and 12 years, respectively. Subjects included 95 (51\%) males and 91 (49\%) females and 15\% of them $(28$ cases) had family history of brucellosis. Animal contact was positive in $17.7 \%$ of children ( 33 cases) while $29 \%$ of them (54 cases) had a history of consumption of unpasteurized dairy products (Table 1).

At enrollment, Wright test was 1/160 in two children and $1 / 40$ in two children and the rest of them had negative Wright test result. Positive Wright test children had 1/40 2ME result. Of the study subject who had negative Wright test, Coombs Wright test was $1 / 160$ in 4 children, $1 / 80$ in 2 children, and 1/40 in 20 children and it was negative in other study subjects. A total of eight children (3.4\%) were seropositive (Wright test of $\geq 1 / 80$ and 2 -Mercaptoethanol ( $2 \mathrm{ME}) \geq 1 / 40$ or Coombs Wright $\geq 1 / 80$ ).

All children were followed up for one year for the appearance of symptoms. Among eight seropositive study subjects, the symptoms manifested in six cases (Table 2).

These patients underwent standard treatment (Trimethoprim-sulfamethoxazole $10 \mathrm{mg} / \mathrm{kg} /$ day of Trimethoprim PO twice daily plus rifampin $15-20 \mathrm{mg} / \mathrm{kg} /$ day PO for 6 weeks). After 2 months of the treatment, 4 patients were $2 \mathrm{ME}$ negative (patients numbers 1, 2, 5, and 6; Table 2) and 2 patients had negative $2 \mathrm{ME}$ result after 4 months (patients numbers 3 and 4; Table 2) of treatment, and all clinical symptoms were resolved.

\section{Discussion}

Brucellosis is a zoonotic disease and, despite all efforts to reduce its incidence by vaccination of cattle and 
pasteurization of dairy products, it is still an important health problem in some parts of the world, especially in Asia and the Mediterranean $[9,10]$. Its prevalence in Iran varies from 0.5 to $10.9 \%$ and its 5 -year incidence rate in the central provinces of Iran is estimated to be $40-50$ cases per 100,000 [11].

Previous studies have shown that zoonosis diseases may cause subclinical or asymptomatic infection in patients with persistent or occupational exposure to sources of the disease [12-14]. This could be due to frequent contact with the pathogen and a relative resistance to it. Identification and treatment of these patients is costly effective if its screening is economically cheaper than treating complications and treatment of patients in which the disease is transmitted by undiagnosed carriers [15].

This study aimed to evaluate the prevalence of asymptomatic brucellosis in children 7 to 12 years old in an endemic city. The results showed that, in endemic areas, asymptomatic brucellosis occurs in children with the incidence of $3.4 \%$. Asymptomatic infection may result from contact with animals harboring low virulence species of Brucella or from less frequent contact with contaminated sources [6]. The importance of this issue is in the early detection, preventing chronic infection and finding the origin of the disease to prevent transmission to others. Zhen and colleagues showed that among 300 adults with continuous contact to animals and their products, 131 cases (45\%) had asymptomatic brucellosis [6]. In another study by Çelebi et al., three members of a family with acute infection were studied by culture and all three members of the family (parents and sister of the patient) were infected with brucellosis. Also, the breast milk culture was positive for bacteria [16].

The most benefit of screening in endemic area is detection of new cases that are unaware of their disease because of lack of symptoms or mild symptoms such as fever and myalgia which did not require medical advice. These cases would not have been recognized without screening. However, early detection and prompt treatment of the disease can provide rapid recovery and prevent complications or sequels [17-19].

In Tabak's study, of 100 family members of patients with brucellosis, 20 cases were seropositive and, among them, 12 cases were asymptomatic and, within 6 to 12 months' followup, none of them had symptoms [20].

However, in the present study, 6 of 8 seropositive children became symptomatic during one year follow-up. Sofian et al. in a study evaluated 163 family members of 50 patients with acute brucellosis in an endemic area of Iran. 9.2\% of family members were seropositive for Brucella agglutinin and, among them, $53.3 \%$ were asymptomatic and $46.7 \%$ were symptomatic. They showed that family members of brucellosis patients are at risk of disease acquisition, and screening of household members provides an effective way for early diagnosis and prompt treatment [3]. Almuneef et al. evaluated 404 household members of 55 patients with acute brucellosis in endemic areas of Saudi Arabia. Of the 404 household members screened, 53 were seropositive; of these 39 were symptomatic, and 9 had Brucella bacteraemia. They showed that screening family members of an index case of acute brucellosis would detect additional cases [21].

\section{Conclusion}

To our knowledge, this is the first study on the prevalence of brucellosis in asymptomatic children. It showed that, in endemic areas, about $4.3 \%$ of children may have asymptomatic brucellosis by which most of them may get symptomatic in short term. It seems that early detection can help timely treatment and prevention of the complications.

\section{Conflict of Interests}

The authors declare that there is no conflict of interests regarding the publication of this paper.

\section{Acknowledgments}

The authors would like to thank all participants who cooperated during the study and Mrs. Fatemeh Hosseinzadeh (Clinical Research Development Center of Qom University of Medical Science's staff).

\section{References}

[1] L. K. Logan, N. M. Jacobs, J. B. McAuley, R. A. Weinstein, and E. J. Anderson, "A multicenter retrospective study of childhood brucellosis in Chicago, Illinois from 1986 to 2008," International Journal of Infectious Diseases, vol. 15, no. 12, pp. e812-e817, 2011.

[2] M. Ulug, Y. Yaman, F. Yapici, and N. Can-Ulug, "Clinical and laboratory features, complications and treatment outcome of brucellosis in childhood and review of the literature," The Turkish Journal of Pediatrics, vol. 53, no. 4, pp. 413-424, 2011.

[3] M. Sofian, L. Safaeipour, A. Aghakhani et al., "Screening of family members of patients with acute brucellosis in an endemic area of Iran," Iranian Journal of Microbiology, vol. 5, no. 3, pp. 215-219, 2013.

[4] T. Buzgan, M. K. Karahocagil, H. Irmak et al., "Clinical manifestations and complications in 1028 cases of brucellosis: a retrospective evaluation and review of the literature," International Journal of Infectious Diseases, vol. 14, no. 6, pp. e469-e478, 2010.

[5] M. H. Salari, M. B. Khalili, and G. R. Hassanpour, "Selected epidemiological features of human brucellosis in Yazd, Islamic Republic of Iran: 1993-1998," Eastern Mediterranean Health Journal, vol. 9, no. 5-6, pp. 1054-1060, 2003.

[6] Q. Zhen, Y. Lu, X. Yuan et al., "Asymptomatic brucellosis infection in humans: implications for diagnosis and prevention," Clinical Microbiology and Infection, vol. 19, no. 9, pp. E395-E397, 2013.

[7] M. R. H. Roushan, M. Mohraz, N. Janmohammadi, and M. Hajiahmadi, "Efficacy of cotrimoxazole and rifampin for 6 or 8 weeks of therapy in childhood brucellosis," The Pediatric Infectious Disease Journal, vol. 25, no. 6, pp. 544-545, 2006.

[8] Y. A. Al-Eissa, "Unusual suppurative complications of brucellosis in children," Acta Paediatrica, vol. 82, no. 11, pp. 987-992, 1993.

[9] G. Pappas, P. Papadimitriou, N. Akritidis, L. Christou, and E. V. Tsianos, "The new global map of human brucellosis," The Lancet Infectious Diseases, vol. 6, no. 2, pp. 91-99, 2006.

[10] M. Sofian, A. Aghakhani, A. A. Velayati, M. Banifazl, A. Eslamifar, and A. Ramezani, "Risk factors for human brucellosis in Iran: a case-control study," International Journal of Infectious Diseases, vol. 12, no. 2, pp. 157-161, 2008. 
[11] S. Farahani, S. Shah Mohamadi, I. Navidi, and M. Sofian, "An investigation of the epidemiology of brucellosis in Arak City, Iran, (2001-2010)," Arak Medical University Journal, vol. 14, no. 7, pp. 49-54, 2012.

[12] L. Silvestro, M. Caputo, S. Blancato et al., "Asymptomatic carriage of verocytotoxin-producing Escherichia coli $\mathrm{O} 157$ in farm workers in Northern Italy," Epidemiology and Infection, vol. 132, no. 5, pp. 915-919, 2004.

[13] M. E. Hellard, M. I. Sinclair, G. G. Hogg, and C. K. Fairley, "Prevalence of enteric pathogens among community based asymptomatic individuals," Journal of Gastroenterology and Hepatology, vol. 15, no. 3, pp. 290-293, 2000.

[14] S. T. David, L. MacDougall, K. Louie et al., "Petting zoo-associated Escherichia coli 0157:h7-secondary transmission, asymptomatic infection, and prolonged shedding in the classroom," Canada Communicable Disease Report, vol. 30, no. 20, pp. 173-180, 2004.

[15] R. S. Quilliam, P. Cross, A. P. Williams et al., "Subclinical infection and asymptomatic carriage of gastrointestinal zoonoses: occupational exposure, environmental pathways, and the anonymous spread of disease," Epidemiology and Infection, vol. 141, no. 10, pp. 2011-2021, 2013.

[16] G. Çelebi, C. Külah, S. Kiliç, and G. Üstündağ, "Asymptomatic Brucella bacteraemia and isolation of Brucella melitensis biovar 3 from human breast milk," Scandinavian Journal of Infectious Diseases, vol. 39, no. 3, pp. 205-208, 2007.

[17] A. Gür, M. F. Geyik, B. Dikici et al., "Complications of brucellosis in different age groups: a study of 283 cases in Southeastern Anatolia of Turkey," Yonsei Medical Journal, vol. 44, no. 1, pp. 33-44, 2003.

[18] G. T. Fosgate, T. E. Carpenter, B. B. Chomel, J. T. Case, E. E. DeBess, and K. F. Reilly, "Time-space clustering of human brucellosis, California, 1973-1992," Emerging Infectious Diseases, vol. 8, no. 7, pp. 672-678, 2002.

[19] Y. M. El Miedany, M. El Gaafary, M. Baddour, and I. Ahmed, "Human Brucellosis: do we need to revise our therapeutic policy?” Journal of Rheumatology, vol. 30, no. 12, pp. 2666-2672, 2003.

[20] F. Tabak, E. Hakko, B. Mete, R. Ozaras, A. Mert, and R. Ozturk, "Is family screening necessary in brucellosis?" Infection, vol. 36, no. 6, pp. 575-577, 2008.

[21] M. A. Almuneef, Z. A. Memish, H. H. Balkhy et al., "Importance of screening household members of acute brucellosis cases in endemic areas," Epidemiology and Infection, vol. 132, no. 3, pp. 533-540, 2004. 


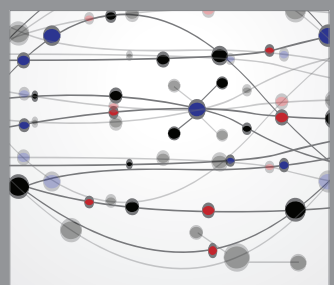

The Scientific World Journal
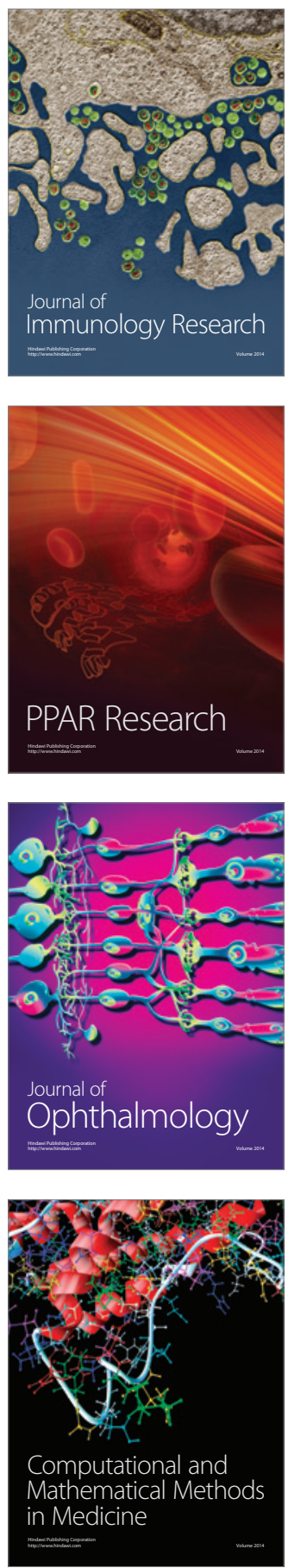

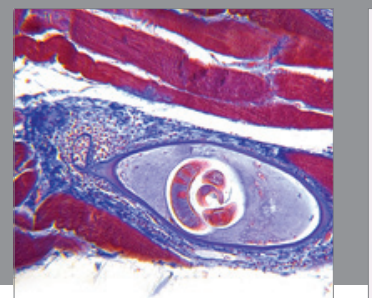

Gastroenterology

Research and Practice
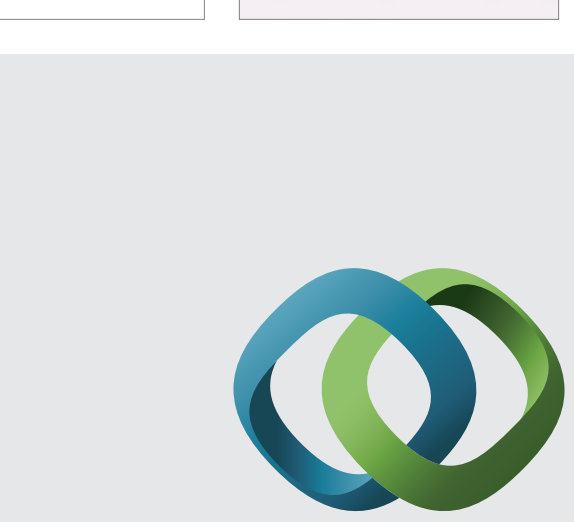

\section{Hindawi}

Submit your manuscripts at

http://www.hindawi.com
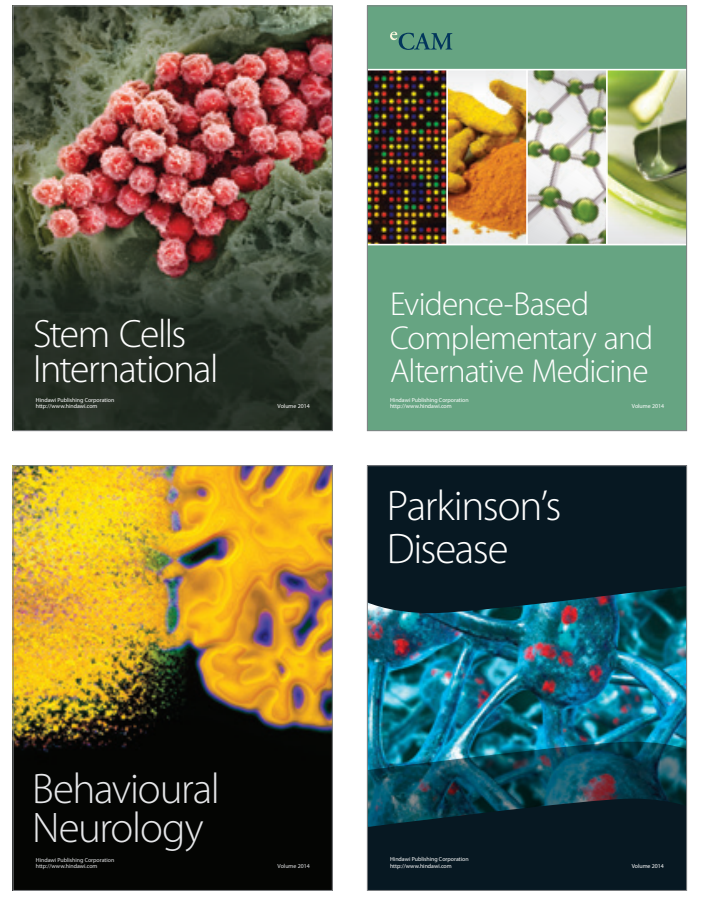
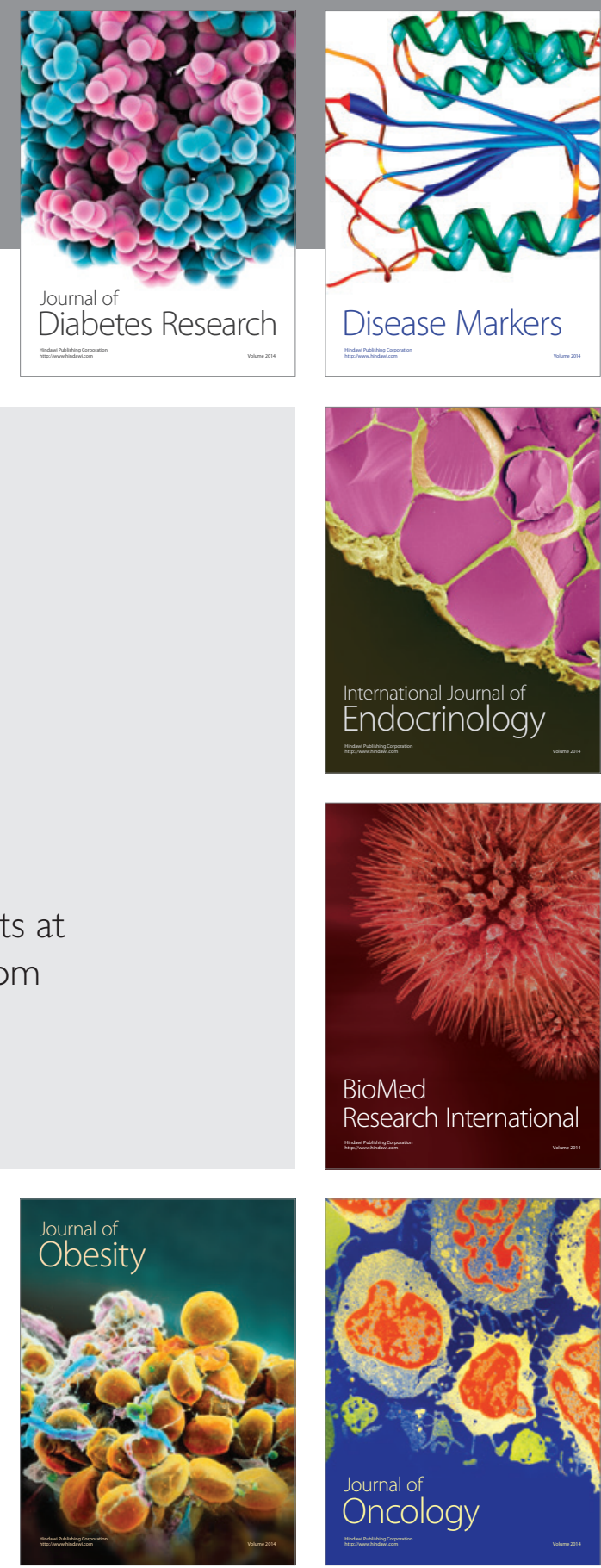

Disease Markers
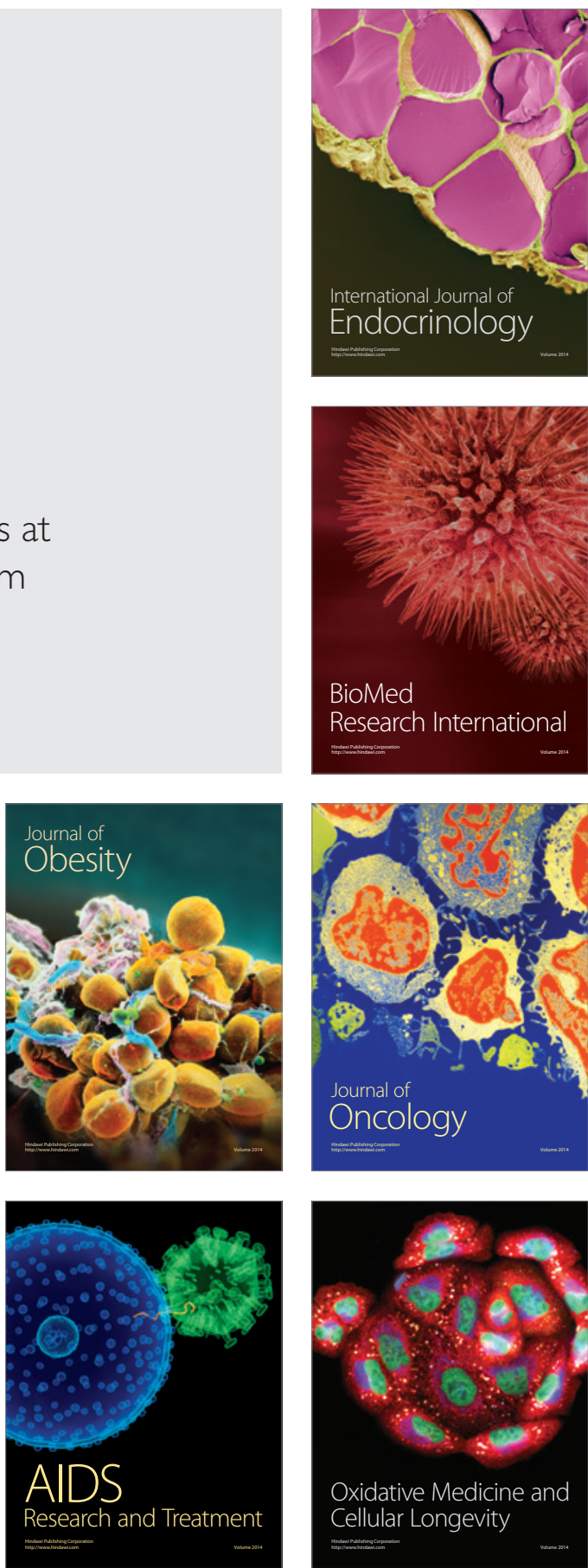